\title{
Phylogenetic and epidemiologic evidence of multiyear incubation in human rabies
}

\section{Citation}

Boland, Torrey A., Declan McGuone, Jenelle Jindal, Marcelo Rocha, Melissa Cumming, Charles E. Rupprecht, Taciana Fernandes Souza Barbosa, et al. 2014. "Phylogenetic and Epidemiologic Evidence of Multiyear Incubation in Human Rabies." Annals of Neurology 75 (1) (January): 155160. doi:10.1002/ana.24016.

\section{Published Version}

doi:10.1002/ana.24016

\section{Permanent link}

http://nrs.harvard.edu/urn-3:HUL.InstRepos:29663469

\section{Terms of Use}

This article was downloaded from Harvard University's DASH repository, and is made available under the terms and conditions applicable to Other Posted Material, as set forth at http:// nrs.harvard.edu/urn-3:HUL.InstRepos:dash.current.terms-of-use\#LAA

\section{Share Your Story}

The Harvard community has made this article openly available.

Please share how this access benefits you. Submit a story.

\section{Accessibility}




\title{
Phylogenetic and Epidemiologic Evidence of Multiyear Incubation in Human Rabies
}

\author{
Torrey A. Boland, MD1, Declan McGuone, MB, BCh, BAO², Jenelle Jindal, MD², Marcelo \\ Rocha, MD, $\mathrm{PhD}^{3}$, Melissa Cumming, $\mathrm{MS}^{4}$, Charles E. Rupprecht, VMD, MS, $\mathrm{PhD}^{5}$, Taciana \\ Fernandes Souza Barbosa ${ }^{6}$, Rafael de Novaes Oliveira, MS ${ }^{7}$, Catherine J. Chu, MD ${ }^{3}$, \\ Andrew J. Cole, MD $^{3}$, Ivanete Kotait ${ }^{7}$, Natalia A. Kuzmina, PhD $^{8}$, Pamela A. Yager, BS $^{8}$, \\ Ivan V. Kuzmin, MD, PhD $^{9}$, E. Tessa Hedley-Whyte, MD $^{2}$, Catherine M. Brown, DVM, MSc, \\ $\mathbf{M P H}^{4}$, and Eric S. Rosenthal, $\mathbf{M D}^{3}$ \\ ${ }^{1}$ Department of Neurological Sciences, Rush University Medical Center, Chicago, IL \\ ${ }^{2}$ C. S. Kubik Laboratory for Neuropathology, Department of Pathology, Massachusetts General \\ Hospital, Harvard Medical School, Boston, MA \\ ${ }^{3}$ Department of Neurology, Massachusetts General Hospital, Harvard Medical School, Boston, \\ MA \\ ${ }^{4}$ Massachusetts Department of Public Health, Hinton State Laboratory, Jamaica Plain, MA \\ ${ }^{5}$ Global Alliance for Rabies Control, Manhattan, KS \\ ${ }^{6}$ Evandro Chagas Institute, Pará, Brazil \\ ${ }^{7}$ Pasteur Institute, Sao Paulo, Brazil \\ ${ }^{8}$ Centers for Disease Control and Prevention, Atlanta, GA \\ ${ }^{9}$ Aravan LLC, Lilburn, GA
}

\section{Abstract}

Eight years after emigrating from Brazil, an otherwise healthy man developed rabies. An exposure prior to immigration was reported. Genetic analysis revealed a canine rabies virus variant found only in the patient's home country, and the patient had not traveled internationally since immigrating to the United States. We describe how epidemiological, phylogenetic, and viral sequencing data provided confirmation that rabies encephalomyelitis may present after a long, multiyear incubation period, a consideration that previously has been hypothesized without the ability to exclude a more recent exposure. Accordingly, rabies should be considered in the diagnosis of any acute encephalitis, myelitis, or encephalomyelitis.

(C) 2013 American Neurological Association

Address correspondence to Dr Boland, Department of Neurological Sciences, Rush University Medical Center, 1725 W Harrison St, Suite 1106, Chicago, IL 60612. torrey_boland@rush.edu.

Potential Conflicts of Interest

A.J.C.: consultancy, Clarus Ventures, Concert Pharmaceuticals, Sage Pharmaceuticals, Eisai Pharmaceuticals; grants/grants pending, NIH National Institute of Neurological Diseases and Stroke. P.A.Y.: royalties, EMD Millipore (Chemicon International). 
A 40-year-old Brazilian man presented to the emergency department with painful arm and leg paresthesias accompanied by myalgias; he was given analgesics and discharged. Over the following week, he developed fever, chills, severe headache, and intermittent confusion. His weakness evolved from predominantly upper extremities to significant gait dysfunction. Three weeks after symptom onset, he was admitted to a hospital with fever, areflexia, and weakness. Lumbar puncture revealed elevated protein $(159 \mathrm{mg} / \mathrm{dl})$, normal glucose, and mild leukocytosis with mononuclear predominance $\left(33 \mathrm{cells} / \mathrm{mm}^{3}, 87 \%\right.$ mononuclear). Broadspectrum antibiotics were administered. Electromyography revealed absent right $\mathrm{F}$ responses. Brain magnetic resonance imaging (MRI) was unremarkable, but MRI of the spine showed abnormal T2 signal from T8 to the conus without T1 enhancement (Fig 1). He was transferred to a tertiary facility. On arrival he appeared toxic, with a temperature of $38.9^{\circ} \mathrm{C}$. Cardiopulmonary examination was unremarkable. No rash or edema was present. The patient was awake but confused. No cranial neuropathy was evident. Strength testing revealed symmetric distal weakness. Sensation was intact. Reflexes were absent except for $1+$ triceps reflexes.

The subsequent 72 hours yielded progressive obtundation requiring intubation. The patient was transferred to the neurocritical care unit, where he was unresponsive to noxious stimuli with intermittent down-beating nystagmus. Pupils were $5 \mathrm{~mm}$ and nonreactive; corneal reflexes were present. He had diffuse stimulus-induced facial contractions but no gag or cough reflex. Extremities remained flaccid to nail bed pressure, and reflexes were absent. He had spontaneous respiratory effort and was hemodynamically stable. Continuous electroencephalographic (EEG) monitoring showed generalized slowing (see Fig 1).

MRI of the brain and spine revealed a new T2 signal abnormality in the cervical cord. Lumbar puncture revealed a lymphocytic cerebrospinal fluid (CSF) leukocytosis (71 cells $/ \mathrm{mm}^{3}, 55 \%$ lymphocytes) and elevated protein $(81 \mathrm{mg} / \mathrm{dl})$. Toxicology and an extensive infectious disease workup were negative. Intracranial pressure was normal by fiberoptic monitoring. Antibiotics were discontinued after microbiological testing was negative. Immunosuppressive therapy including steroids and intravenous immunoglobulin was administered to treat possible autoimmune postinfectious encephalomyelitis. His neurological status continued to decline, with loss of remaining brainstem reflexes by hospital day 5 .

On day 5, EEG showed diffuse slowing with frequent waxing and waning of bifrontal sharp wave discharges with triphasic morphology, evolving by day 11 to diffuse background attenuation with no reactivity to further attenuation by day 15 , albeit not meeting brain death criteria for electrocerebral silence. Visual evoked potentials were present and reproducible on hospital day 8. Day 9 electromyography demonstrated fibrillation potentials, absent sensory and motor responses, and positive sharp waves, consistent with severe sensorimotor peripheral neuropathy. On day 12, a third MRI of the brain showed new restricted diffusion of cerebral white matter with leptomeningeal enhancement, progressing to prominent temporal and perisylvian cortical edema by day 15 . On day 13 , a frontal brain biopsy showed diffuse subacute ischemic damage with minimal perivascular and parenchymal chronic inflammation, consisting predominantly of $\mathrm{CD}^{+} \mathrm{T}$ cells, occasional $\mathrm{CD} 138^{+}$ plasma cells, and rare $\mathrm{CD} 20^{+} \mathrm{B}$ cells. No vasculitis, demyelination, micro-organisms, or 
features of viral encephalitis were found (Fig 2). A sural nerve biopsy performed on the same day showed extensive peripheral nerve Wallerian degeneration. The patient continued to receive maximal support without signs of improvement. Rabies virus-neutralizing antibodies were retrospectively detected in CSF 24 days before death $(0.56 \mathrm{IU} / \mathrm{ml})$, and in serum 8 days before death $(22.0 \mathrm{IU} / \mathrm{ml})$, by rapid fluorescent focus inhibition testing. ${ }^{1}$ Unfortunately saliva and nuchal biopsy samples collected at that time were noninformative because of delay in sample arrival resulting in a break in the cold chain for these samples. The patient died on hospital day 28 after the family elected comfort care and terminal extubation.

An unrestricted autopsy was performed. The brain was dusky gray and liquefied with obliteration of all anatomic landmarks, consistent with severe hypoxic/ischemic injury. Histology revealed disseminated encephalomyelitis with widespread chronic inflammation, gliosis, and diffuse hypoxic-ischemic damage. The spinal cord was better preserved, with striking gray matter perivascular lymphocytic cuffing, microglial nodules, and loss of alphamotor neurons. Negri bodies were identified in a few anterior horn cells. Dorsal root and multiple sympathetic nervous system ganglia showed moderate ganglionitis, with mild ganglion cell loss but no viral inclusions. Peripheral nerves showed widespread severe axonal loss and demyelination, with patchy mild endoneurial chronic inflammation. Autopsy also revealed mild lymphocytic myocarditis, with focal intracardiac lymphocytic neuritis (Fig 3).

Fresh frozen brain tissue obtained at autopsy was submitted to the Centers for Disease Control and Prevention, where the presence of rabies virus antigen was detected by direct fluorescent antibody testing. ${ }^{2}$ Antigenic typing with antinucleocapsid monoclonal antibodies revealed a Latin American dog rabies virus variant. ${ }^{3}$ Viral RNA was amplified by reverse transcription polymerase chain reaction, and complete viral genome sequencing, as described elsewhere, ${ }^{4}$ revealed a sequence with retained identity typical of canine rabies viruses, without alteration of known antigenic sites (Genbank KC737850). With 99.3 to $100 \%$ identity based upon partial nucleoprotein gene sequences available for comparison, phylogenetic analysis showed a canine rabies virus variant from the patient's home state of Rondônia, Brazil (see Fig 3), coinciding with the timing of his residency there. Further history from the patient's family indicated he was a carpenter with no recent exposures. Of note, 30 days prior to admission he had started using anabolic steroids. There had been no travel outside of Massachusetts for the prior 8 years or contact with animals transported from Latin America. However, a family member reported that the patient had been in contact with an abnormally behaving dog prior to his immigration, striking the animal in the head with a piece of wood and dragging the carcass without gloves, although without a known bite or scratch.

The Massachusetts Department of Public Health was contacted, and postexposure prophylaxis and vaccination were provided to a number of social and occupational contacts as well as to several health care workers. 


\section{Discussion}

We present a case of paralytic rabies, with phylogenetic and epidemiologic evidence of a prolonged incubation period before initial presentation. Once an exposure has occurred, rabies virus may remain locally at the inoculation site before movement to the central nervous system along peripheral nerves. The usual incubation period is 1 to 6 months. Incubation periods up to 6 years postexposure have been reported with supportive genetic or antigenic data. ${ }^{5-7}$ Other reports hypothesize that longer incubation periods may occur (up to 25 years); however, these cases occurred in regions where rabies is endemic and the possibility of re-exposure cannot be excluded. ${ }^{8,9}$ In the United States, enzootic canine rabies virus variants have been eliminated, ${ }^{10}$ although unvaccinated dogs may be infected with other rabies virus variants. The patient reported here had lived in Massachusetts for 8 years without any known foreign travel and had genetic viral sequencing demonstrating a virus present only in Latin America. In addition, this patient experienced a prolonged prodromal period, longer than the typical 7 to 10 days. Others have hypothesized that patients with prolonged incubations may have slowed viral replication, ${ }^{11}$ which if present could also result in a protracted prodromal period.

Additionally, epidemiologic evidence supports that there had been no re-exposure from unreported travel. According to the Pan American Health Organization, cases of rabies in dogs in Brazil decreased from 289 to 5 between 2003 and 2011. Human cases of rabies attributable to a canine virus variant declined from 14 to 2 over the same time period. By surveillance activities, the last identification of a rabid dog in the patient's city of origin was 2003, and the last rabid dog in Rondônia State was documented in 2008. This decrease indicates that the alternative explanation of a more recent exposure to this virus, either through undocumented travel to the patient's state of origin, or through importation of a dog from that area, is similarly unlikely. These epidemiologic data together with the aforementioned phylogenetic identification of the virus provide support for a prolonged incubation period of $>8$ years in our patient.

This case is also unusual because of the extent and striking severity of parenchymal inflammation in the spinal cord, the degree of which is unusual for most rabies virus infections. Although intense inflammation has been described in previously reported cases of paralytic rabies, this tends to be more restricted in distribution than seen in the current case. Although differences in inflammatory patterns exist between paralytic and classic syndromes, ${ }^{12}$ it is unknown whether inflammatory patterns vary with the incubation period, or whether they resulted in this case from the prolonged hospital course and supportive care. The patient's anabolic steroid supplementation beginning 1 month before hospitalization is of uncertain significance. Although anabolic steroids have been reported to reduce maturation and stimulation of lymphocytes and decrease antibody formation, ${ }^{13,14}$ it is unclear whether the patient's steroid intake played a role in the activation of rabies virus.

In conclusion, this case represents the longest confirmed incubation period of rabies known to date. The extensive phylogenetic and epidemiological workup conducted strengthen the data and provide multiple methods of support for the previously speculative hypothesis that rabies may present after multiple years of incubation. Consideration of rabies in the 
evaluation of rapidly progressive encephalitis, myelitis, or encephalomyelitis is critical for appropriate risk assessment of patient contacts and to guide prognosis, although the treatment outcomes of delayed progression remain unknown.

\section{References}

1. Smith, JS.; Yager, PA.; Baer, GM. A rapid fluorescent focus inhibition test (RFFIT) for determining rabies virus-neutralizing antibody. In: Meslin, FX.; Kaplan, MM.; Koprowski, H., editors. Laboratory techniques in rabies. 4. Geneva, Switzerland: World Health Organization; 1996. p. 181-192.

2. Dean, DJ.; Abelseth, MK.; Atanasiu, P. The fluorescent antibody test. In: Meslin, FX.; Kaplan, MM.; Koprowski, H., editors. Laboratory techniques in rabies. 4. Geneva, Switzerland: World Health Organization; 1996. p. 88-93.

3. Smith JS. Rabies virus epitopic variation: use in ecologic studies. Adv Virus Res. 1989; 36:215253. [PubMed: 2472046]

4. Kuzmin IV, Wu X, Tordo N, Rupprecht CE. Complete genomes of Aravan, Khujand, Irkut and West Caucasian bat viruses, with special attention to the polymerase gene and non-coding regions. Virus Res. 2008; 136:81-90. [PubMed: 18514350]

5. World Health Organization. WHO expert consultation on rabies: first report. Geneva, Switzerland: World Health Organization; 2005.

6. Smith JS, Fishbein DB, Rupprecht CE, Clark K. Unexplained rabies in three immigrants in the United States: a virologic investigation. N Engl J Med. 1991; 324:205-211. [PubMed: 1985241]

7. Centers for Disease Control and Prevention. [July 25, 2013] CDC confirms rabies death in organ transplant recipient. 2013. Available at: http://www.cdc.gov/media/releases/2013/ s0315_rabies_organs.html

8. Shankar SK, Mahadevean A, Sapico SD, et al. Rabies viral encephalitis with probable 25 year incubation period. Ann Indian Acad Neurol. 2012; 15:221-223. [PubMed: 22919200]

9. Gardner AM. An unusual case of rabies. Lancet. 1970; 2:523. [PubMed: 4194966]

10. Blanton JD, Palmer D, Rupprecht CE. Rabies surveillance in the United States during 2009. J Am Vet Med Assoc. 2010; 237:646-657. [PubMed: 20839985]

11. Hemachudha T, Ugolini G, Wacharapluesadee S, et al. Human rabies: neuropathogenesis, diagnosis, and management. Lancet Neurol. 2013; 12:498-513. [PubMed: 23602163]

12. Chopra JS, Banerjee AK, Murthy JMK, Pal SR. Paralytic rabies: a clinico-pathological study. Brain. 1980; 103:789-802. [PubMed: 7437890]

13. Mendenhall CL, Grossman CJ, Roselle GA, et al. Anabolic steroid effects on immune function: differences between analogs. J Steroid Biochem Mol Biol. 1990; 37:71-76. [PubMed: 2242353]

14. Marshall-Gradisnik S, Green R, Brenu EW, Weatherby RP. Anabolic androgenic steroids effects on the immune system: a review. Cent Eur J Biol. 2009; 4:19-33. 

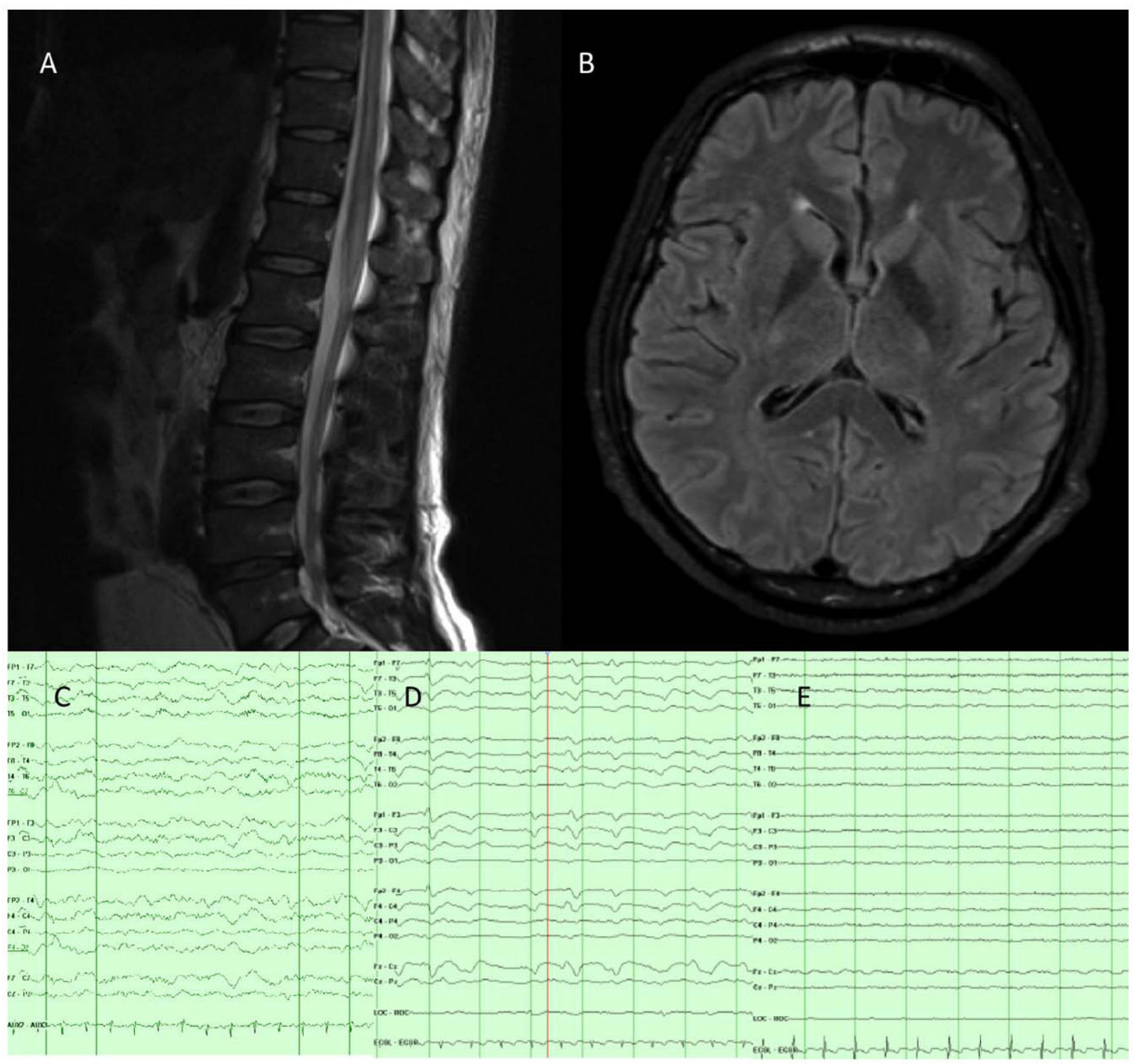

FIGURE 1.

Clinical studies: magnetic resonance imaging (MRI) of the brain and thoracic spine and electroencephalography (EEG). (A) MRI of thoracic and lumbar spine, T2 sequence, showing a nonenhancing T2 hyperintensity extending from the conus to the T8-9 level. (B) Admission MRI of the brain, fluid-attenuated inversion recovery sequence, showing normal anatomy without signal changes. (C) EEG on admission with diffuse slowing. (D) EEG on day 5 with triphasic morphology. (E) EEG on day 11 with diffuse attenuation. [Color figure can be viewed in the online issue, which is available at www.annalsofneurology.org.] 

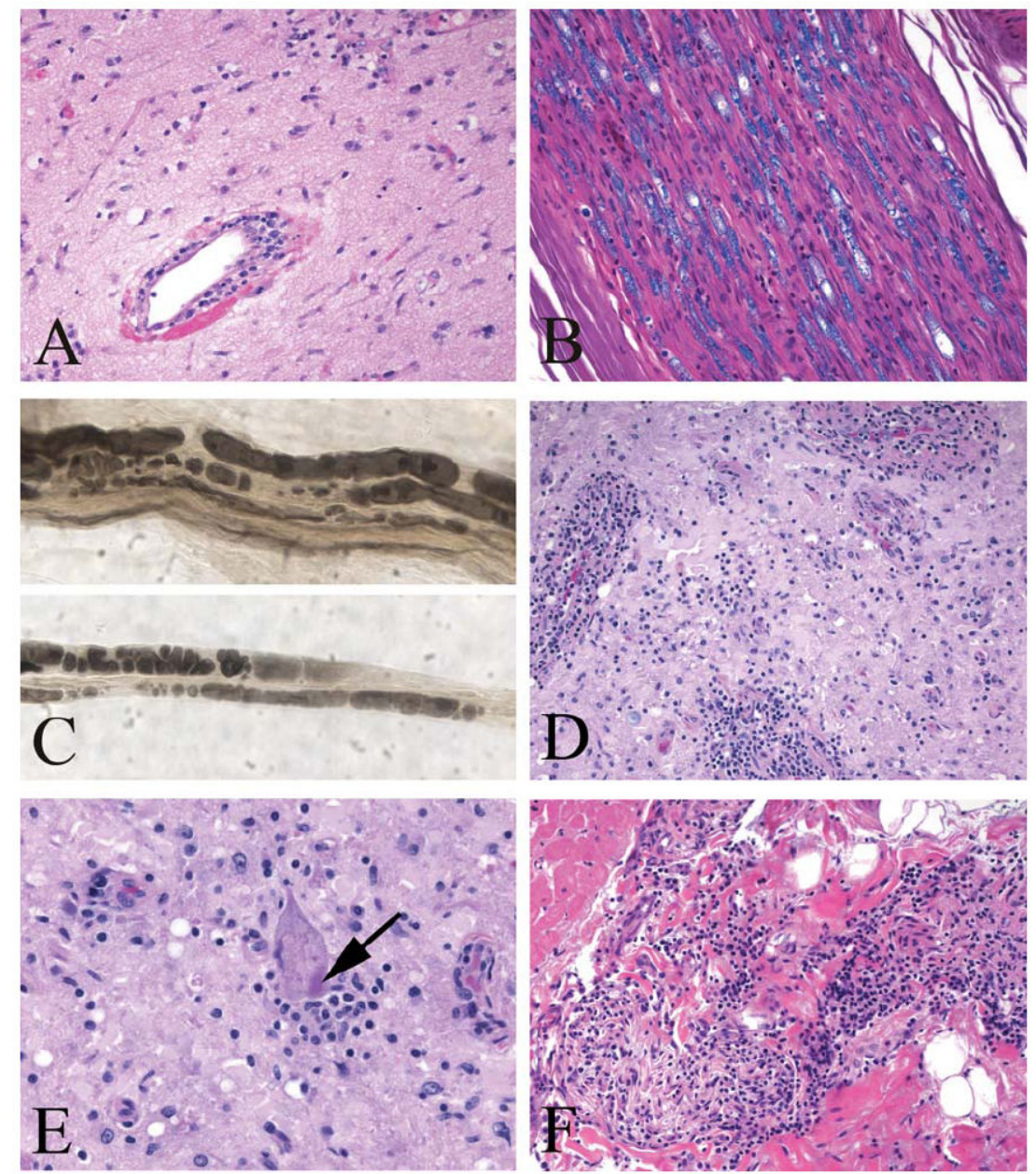

FIGURE 2.

Premortem brain, sural nerve biopsy, and postmortem spinal cord and myocardium. (A) Brain biopsy showing widespread subacute ischemic damage with rarefied neuropil and perivascular lymphocytic infiltrates (hematoxylin and eosin [H\&E]). (B) Sural nerve biopsy showing breakdown of myelin (Luxol fast blue/H\&E) with (C) Wallerian degeneration on a teased nerve fiber preparation (osmium fixed nerve). (D) Spinal cord ventral horn with neuronal loss and prominent perivascular and parenchymal lymphocytic infiltrates (Luxol fast blue/H\&E). (E) Negri body in a residual spinal anterior motor neuron (arrow; Luxol fast blue/H\&E). (F) Interatrial cardiac septum with lymphocytic inflammation (H\&E). [Color figure can be viewed in the online issue, which is available at www.annalsofneurology.org.] 


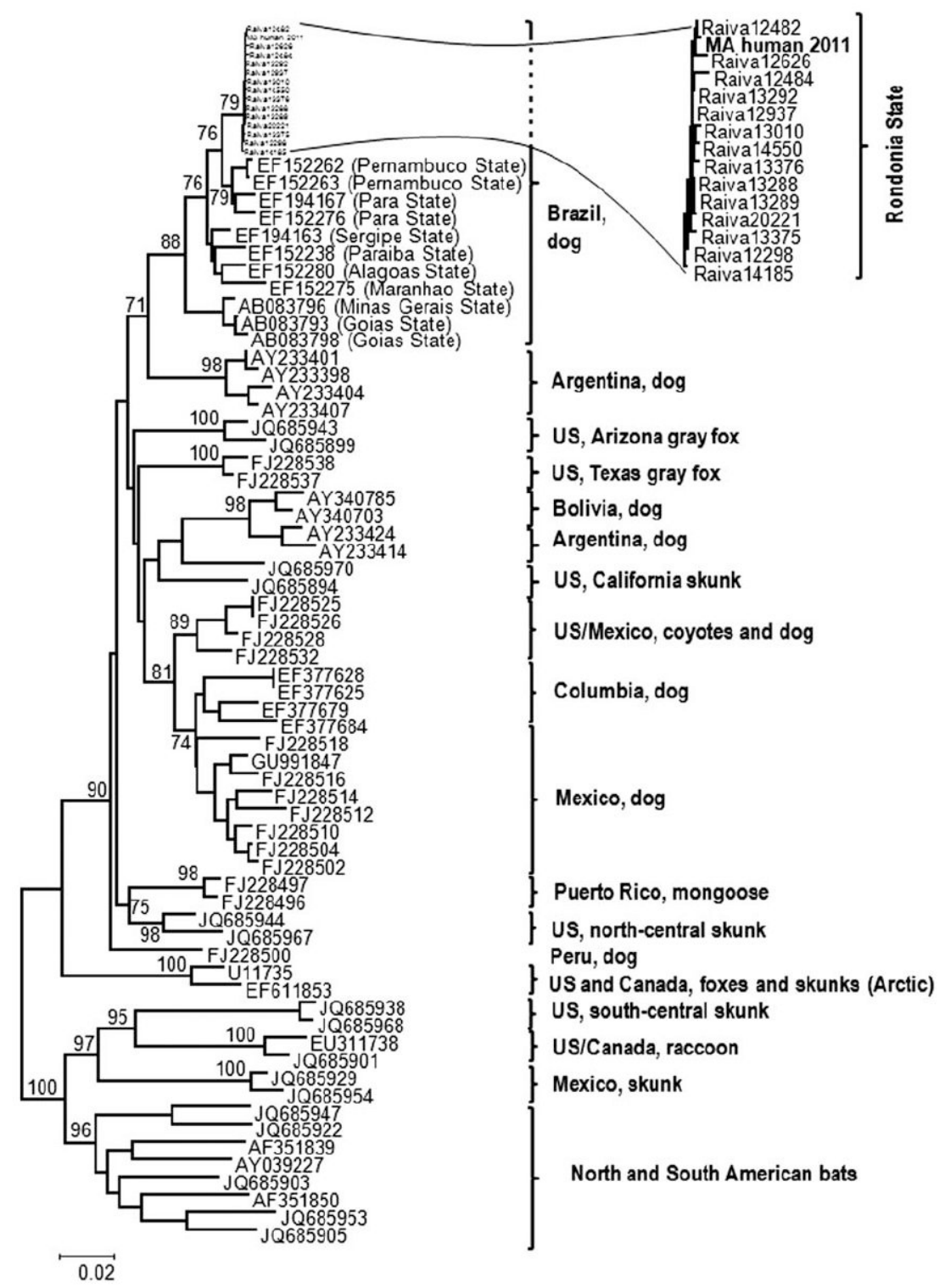

FIGURE 3.

Phylogenetic tree of rabies virus lineages documented in the Americas. The phylogenetic tree is based on nucleoprotein gene sequences (complete and partial, with pairwise gap deletion), demonstrating the position of the human isolate (MA human 2011) in the context of rabies virus lineages documented in the Americas. Significant bootstrap values (>70) are shown for key nodes. 